\title{
The Thoughtful University: A Feasible Utopia
}

\author{
Ronald A. Barnett \\ Emeritus Professor, University College London, Institute of Education, UK \\ ron.barnett@ucl.ac.uk
}

\begin{abstract}
Philosophers have long made allegations of a thoughtlessness in the world and, in the wake of their charges, critiques of thoughtlessness on the part of the university have also been made. Explanations for such thoughtlessness are rooted in both $e x$ ogenous and endogenous sources. Thinking has not been vanquished entirely from the university but rather a malign thoughtlessness has descended on it. Drawing especially on Bhaskar's Critical Realism, a conception of the thinking university is proffered here that both recognizes the deep structures at work and opens a sense of the university as an agent. Four criteria of university thoughtfulness are proposed. The prospects for such a cognitive culture emerging are explored, two phenomena being identified; first, that the social ontology of the university is widening and second, that contra postmodernism, universals associated with the university are increasing. Further, the constellation of reason has been displaced by the constellation of utility but a new constellation is struggling to emerge, which is calling for thought on the part of the university, namely the constellation of otherness. The thinking university is, therefore, a feasible utopia, its legitimacy standing up to the rigorous scrutiny of six conditions of adequacy. The thinking university is already living in the real world.
\end{abstract}

\section{Keywords}

university - social ontology - universals - thought - reason - feasible utopia 


\section{Introduction ${ }^{1}$}

For a long time in philosophical quarters, at least, the suggestion has come that humanity is in a condition of thoughtlessness. Those critiques have characteristically taken the form either of a lack of thoughtful agency (for example, in Nietzsche and Heidegger) or the constraint of a thought-less set of social structures (exemplified in the Frankfurt School of Critical Theory, in the work of Horkheimer, Adorno and Marcuse). Inferences as to an impoverishment of thought can be glimpsed, too, albeit in different ways, in the more contemporary work of Habermas, MacIntyre, Zizek and Stiegler.

The contemporary university cannot be immune from such charges and, indeed, some have criticized the university for being so incorporated into the state and its audit apparatus that it has succumbed to the non-thinking of the trope of "excellence" (as in Readings) or to the dominant ideologies of capitalism and militarism (as in Giroux) or to helping to sustain the wider 'stupidity' that attaches to the global capitalist economy of the present century (as in Stiegler).

Against the background of these and related critiques, I want to examine the modern university and its evolving knowledge cultures. Three epistemic cultures - to borrow a term from Knorr Cetina, 1999; 2013 - may be discerned: firstly, those of the intellectual cultures within and across the disciplines and academic practices; secondly, of the academic culture of the university as such, of its conception of academic work, and the ways in which it supports its knowledge activities (and not only the respective weight it apportions to research and to teaching, but also the ways in which it might itself constitute or open a space for reasoning); and, thirdly, of the self-reflexive culture of the university, of its capacity to discuss and seriously reflect upon itself as a university, and its place and responsibilities in the world (if any).

Such a wide canvas cannot be covered in the space of a single paper and, in what follows, while saying something about each of these knowledge cultures, I shall primarily focus on the second and third, namely the cognitive culture of the university (as I wish to term it) and the capacity of universities to reflect upon themselves and their stance in and towards the world. I run these two matters together since we cannot seriously examine the capacity of universities to reflect upon themselves unless we also have some sense as to the shifting character of academic cognitive culture. Only thereby can we properly open up the scope that such academic reflexivity should possess.

1 My thanks go to Claudia Ruitenberg, who offered very helpful advice on the drafting of this paper. 
The very matter of the university as an institution that is thoughtful (or is itself thinking) has not been much examined. Several decades since it was made, Heidegger's intimation - that the university does not think much about thinking - is still in evidence. Moreover, the matter has not received much attention in the literature. Consequently, an inquiry such as this - into the thoughtful university - has to assemble resources, their not being readily to hand. Concepts and issues that are drawn upon include structure and agency, the university having a social ontology, the significance of universals, and conflict and antagonisms.

The route I shall take will be to examine the forces at work that are influencing academic cognitive culture and thinking in the university, and I shall distinguish between those forces external to the university - exogenous forces and those that are internal to universities - endogenous forces. I go on to draw out Heidegger's views on thinking and note the implication there that our understanding of thinking is generally deficient, not least in the university. I go on to consider how and in what ways "the thoughtful university" might be glimpsed but - by calling on Roy Bhaskar's philosophy of Critical Realism indicate challenges confronting its specification. Then - and drawing on a book by Judith Butler, Slavoj Zizek and Ernesto Laclau - I shall develop the suggestion of the university as an antagonistic but universal space. And I shall press on to my major thesis that dispute over the very framing of the thoughtful university may come to constitute the university as a kind of feasible utopia.

2 Thoughtlessness and the University

The suggestion that humanity is in a condition of thoughtlessness is far from new, and stretches back well before Heidegger and onwards to the contemporary time. To put just one frame on the matter, and a modern frame at that, we may cast the suggestion in terms of structure and agency. On the one hand, critiques have taken the form of a pointing to a lack of thoughtful agency. Human beings desist from thought about themselves, being too weak to take responsibility for their fate (Nietzsche) or are held in the sway of the "they" (Heidegger) or succumb to "bad faith" (Sartre). On the other hand, humanity is subject to overwhelming structures, whether in the form of instrumental reason (Horkheimer and Adorno), repressive tolerance (Marcuse), or distorted communication structures (Habermas).

It is only right that the contemporary university should be brought up against these charges and some have been acting for the prosecution. In one of the most influential texts of modern times, Readings (1997) observed that the decline of 
the nation-state has been accompanied by a decline in culture. In turn, Readings suggested (1997: chapter two) that the university, once a site of culture, has been caught up in vapid talk of "excellence" that acts at most as a shield for a non-comprehending audit regime. More recently, Stiegler $(2014 ; 2015)$ has accused the university of buttressing and even extending the general "stupidity" that characterises the knowledge economy in the twenty-first century.

If such critics fall more on the structure side of the matter, the advocates of critical pedagogy - such as Giroux and McLaren - have been keen also to play up the agency side. Starting precisely from a dual sense of modernity as characterised by oppressive ideologies and power structures and of higher education as sustaining those structures, radical pedagogy gains its spurs from attempting to inject countervailing resistance in higher education through empowering students to become their own agents and to take on critical stances in the world (McLaren and Jaramillo, 2010; Giroux, 2015).

Other recent and contemporary voices occupy more ambiguous positions here. For MacIntyre, by implication at least, universities are institutions that are losing - or have lost - their being sets of practices with their own virtues and ways of going on, in fulfilling their internal goods (MacIntyre, 1985: 185-195). As a result, "the contemporary research university is ... by and large a place in which certain questions go unasked..." (MacIntyre, 2011: 74).

Taken together, these critiques - which are only among the more prominentamount to an astonishing set of commentaries on the contemporary university as a site of knowledge culture. The very institution that is supposedly sustaining and advancing thoughtfulness turns out to be harbouring thoughtlessness. The charges, though, are alerting us to different backgrounds that are contributing to this thoughtlessness.

Implicit in the observations just made is a distinction between thoughtlessness in the wider world, of which the university is now part and which the university reflects, and a thoughtlessness that may be fairly said to be characteristic of universities themselves. The first form of thoughtlessness - an exogenous form of thoughtlessness - may be glimpsed in phenomena that import certain features of the world into the university. These include the marketization of higher education, in which the pedagogical relationship takes on aspects of a market relationship, and in which the student-as-customer comes to have expectations of the university as a provider of a marketable good, especially that of the degree certificate (Molesworth, Scullion and Nixon, 2011). 
Under those circumstances, it is hardly surprising if there develops a pedagogy-of-safety, in which both university teachers and students limit their intellectual horizons in order to reach the mutually desired goal. In England, one of the most marketized systems of higher education in the world, almost three-quarters of students are gaining "good degrees", in the upper orders of the degree classification system. More generally, "critical thinking" is tending to disappear as a proclaimed mark of higher education (being absent from university web-sites) and empirically is seen to be weakly developed, if at all, in university programmes of study (Davies and Barnett, 2015:3-5). Instead of being a voyage into strangeness so as to gain "cognitive perspective" (R S Peters, 1970), minds remain within parochial horizons.

These externally imported features of market-driven thoughtlessness extend into the university's wider academic life. National research evaluation exercises exacerbate competition between institutions. Accordingly, in their efforts to secure their positions in the resulting national and global league tables, academics will respond to the criteria in play. Papers in "world-leading" journals will come to have safety attaching to them. A measure of novelty is valued as "innovation" but attempts to critique existing paradigms of thought and disciplinary framing carry too much risk. Added to that is the sheer pressure to produce papers (exacerbated by the increasing use of metrics and management surveillance (cf Wilsdon, 2015)), which in turn is likely to lead to research capability developing through a very close focus on particular topics. "Expertise" comes to demand a mastery of discrete phenomena and their associated research literatures.

Bloom (1987) wrote of the closing of the American mind. What is in prospect here, though, is a closing of the academic mind. Much less a space for the kind of spacious reflection and thought which Newman (1976) termed "philosophical", now the university is in danger (Leavis's (1969:169) term can be used without flinching) of becoming a place of utility in the precise sense that it has specific production functions (of knowledge and skills oriented to the changing economy) and it is an engine for fulfilling those functions.

The argument here should not be misunderstood. It is not that the kinds of features being picked out here describe every university in toto. To the contraryand this is a crucial part of the argument - universities, programmes of study, disciplines and lines of research - differ profoundly in the extent to which these phenomena (of entrepreneurialism and cognitive efficiency) are present. The total ecology is characterised not just by difference but by multifarious differences that are not fully understood. But we are entitled to observe, especially with the university having become a global institution and playing its part in the formation of "cognitive capitalism" (Peters, 2009, 2013; Boutang, 
2011), that there are global forces at work that are affecting universities worldwide. And these forces are marked by a limiting and repositioning of cognitive horizons, both in teaching and in research.

To such exogenous forms of university thoughtlessness, we should also observe the presence of more endogenous forms of thoughtlessness, those that can be fairly be laid more at the door of the university itself. These are apparent in various aspects of academic life. They are evident in its intellectual life, in the thoughtlessness sometimes to be found between disciplines, where there is not merely a blankness or non-comprehension but more perniciously, a disinclination to recognize the value of another field. Kant (1992/1798) implied as much in observing a conflict of the faculties but the tacit set of antagonisms that he discerned has given way to an overt antipathy that goes well beyond that of the two cultures of the sciences and the humanities.

Intuitively, it might be felt that such antipathy is the greater the more distant, epistemologically, one field is from another. But there can often be little love between neighbours, as cognate departments feel their rivalry all the more keenly. But disparagement and thoughtlessness may even break out within a field. (The philosophers in the University of Sydney split into two departments, with those favouring Anglo-Saxon and Continental traditions unable to engage with each other, though later re-uniting (Critchley, 2001: xv).)

This endogenous thoughtlessness can be observed in more pernicious ways. Where pedagogical relationships come to take on a market-like character and where teachers are in part dependent on students' appraisals, we may surmise that teaching will not remain unaffected. In turn, pedagogical situations designed, for example, to promote students' criticality (and so place them in challenging situations) are likely to be avoided. Thought is to be avoided. But actual pedagogical approaches are likely to vary: even within a department, faced with similar externalities, academics are likely to respond in different ways, with an array of pedagogical stances being taken. Some teachers will explore and experiment in their efforts to develop students' criticality while other teachers in the same situation may hardly think about criticality, being focused on students' assimilation of material and their skill acquisition.

Thinking as Dwelling: Heidegger's Insights

Against these initial and somewhat critical observations, what might it mean, then, for the phrase "the thinking university" to have application in the world? The phrase presents with a double difficulty as to the nature of "university" and of "thinking". Both matters preoccupied Heidegger, especially in his book 
(2004/1954) What is Called Thinking? He observed that "In universities especially the danger is still very great that we misunderstand what we hear of thinking." (Basic Writings, 2007/1978, ch IX, "What Calls for Thinking”: 378). But what, for Heidegger, is thinking? "Thinking is thinking only when it pursues whatever speaks for a matter" (ibid, 378). Further: "We are trying to learn thinking ... it is a craft ... We must learn thinking, because our being able to think ... is still no guarantee that we are capable of thinking" (ibid, $380-81$ ).

Heidegger goes on directly to address the question "what is called thinking?", and identifies several meanings and, in particular, goes on to pursue the further question, namely "What is it that calls on us to think?" (p. 388) and he suggests that this is a matter of that which is "thought-provoking" (p. 390). And this provoking of thought "entrusts thought to us as our essential destiny". (p. 391)

Elsewhere, Heidegger connects "thinking" with "building" and "dwelling": "Building and thinking are, each in its own way, inescapable for dwelling" (Poetry, Language, Thought, 2001:158) and he suggests that "Thinking must first learn what remains reserved and in store for it, what it is to get involved in. It prepares its own transformation in this learning." (Basic Writings, ch XI, "The End of Philosophy and the Task of Thinking", 2007:436).

"Learning to think", being "provoked to think", "dwelling", getting "involved in", speaking "for a matter" and preparing "its own transformation": here then are some of the concepts and ideas in Heidegger's thinking about thinking. But note again that opening reflection of his, that in universities, "we misunderstand what we hear about thinking". Presumably, such a misunderstanding arises because what is termed "thinking" in universities does not match the elements that comprise thinking (as Heidegger sees it). Universities - it may seem - are not characteristically institutions where "dwelling", being "provoked to think", getting "involved in", speaking "for a matter" and preparing for its own transformation are understood to be part of thinking.

This kind of thoughtfulness, this "dwelling", we may then wager, is disappearing from universities. This is not a new phenomenon but it has almost certainly accelerated in the past half century or so (since Heidegger made his observations on the matter). Universities are now saturated by time but yet are without time. Newman would devote himself - even as a student - to around ten hours of sustained reading a day (in the mid-nineteenth century). That kind of scholarship would barely be contemplated as a proper form of academic life today. It is not just the number of hours given to such scholarship, it is the 
very act itself. Dare an academic be seen reading in his/her room today, as the registrar and estates manager pass along the corridor, conducting an inventory of space usage? The activity itself - reading - is no longer accepted as a proper activity on campus. If it has to be done, then let it be done privately, invisibly.

A number of phenomena are at play here. The act of reading is an internal, invisible act, when the university of today has to exhibit busyness. In this performative university, reading becomes a subversive act. Activities, events, happenings and movements have to be apparent. Universities have to proclaim and to give a show of their changing character, their dynamism, their excitement and their impact. Their promotional videos would be dull affairs if they were to show reading, thinking, and contemplation.

But the academic life conspires with this Weltanschuung. The bibliographies of papers grow in length and perhaps in inverse proportion to the extent to which their sources are the subject of deep interrogation. Search engines can generate huge lists of apparently relevant sources. In the process, scholarship turns into the skills of data assembly and manipulation. In the near future, in this unthinkingness, doubtless algorithms will be able to generate academic papers as a form of digital pastiche via an assemblage of stock words and phrasings.

A yet deeper malaise emerges here. In this busyness and freneticism, the link between universities and knowledge weakens. How might this be? Surely, the journals multiply, their numbers of issues per year keep expanding and the numbers of academic monographs shows little sign of flagging (even if sales are increasingly on-line and printed "on-demand"). The sheer volume of academic published output continues to expand. But this very eruption of activity contains problematic features. One is that of "ignorance explosion", as it was brilliantly named by Lukasiewcz (1994), marked by the sheer weight of material that exceeds full comprehension (an infinite expansion plus finite human brains), the rapid obsolescence of material in many fields, and the challenges of bringing material together to address problems requiring interdisciplinary workings. The pool of the known unknowns grows remorselessly.

But the phenomenon - of ignorance - is wider still. For our knowledge systems are inadequate in the face of the interplay of complex environmental physical, human, technological and institutional - features that Beck (1992) termed "the risk society". To all this is added the turbulence brought about by the digital age, in which "chronoscopic time" (Hassan, 2003), speed becomes a form of control (Virilio, 2005:65). When the analogue workings of the human brain are confronted with an overload of digital material, it is all too easy for the resulting mismatch to be felt and manipulated by organisations as a personal inadequacy. Unmanageably, the emails pile up twenty-four hours a day 
while learning analytics manipulate student life in hidden ways. Here lie forms of personal and organisational non-comprehension that have barely been examined, and which are acutely felt in universities.

Universities remain faithful to their mediaeval origins in many ways and it may be that they are inadequate knowledge systems for addressing the complexity of many issues confronting this small planet in the twenty-first century. If they were adequate, we might expect to have seen the level of creativity rise but the evidence is that societal creativity has fallen over the past century (Murphy, 2009). In a digital age, universities are becoming mere machines for organizing and making accessible existing knowledge rather than producing fundamental revolutions in our knowledge frameworks. Seldom do mission statements deploy concepts of knowledge, reason, and truth, and even more seldom too those of criticality, creativity and dialogue. There may be allusions to "innovation", "breakthroughs", "world-leading research", "patents" and "finding cures" but the tone characteristically adopted is that of knowledge competition and exploitation. There is little interest, it appears, in thinking through the challenge of creating quite new ways of understanding the world. Universities no longer have it as a high priority to be seen associating themselves with the constellation of creative cognition - as we may term it.

But there is perhaps a deeper phenomenon at work here. It is a matter of cognitive risk. Academic life is becoming an epistemically risk-free zone. Paul Feyerabend (2001) touched on the matter in his final reflections: the earth and - over the centuries - cultures have created a world of "abundance", overflowing with insights, ways of appreciating the world, symbolic systems and modes of interpretation. And yet, our knowledge systems by and large stick with the conventional, as developed in the systems of knowledge institutions. As a result, our understanding and our sense of the world are unduly limited. There is a hesitancy in venturing forward into new lands.

There are, in all this, strains of added thoughtlessness on campus. Partly it is a matter of self-enclosure, drawing in boundaries and playing safe. Partly, it is a matter of rushing, of not having the time to think. And partly, too, it is a matter of a shift in orientation towards ends, impact, and output. The spaciousness, carefulness, indwelling, quietness, cognitive hard work and courage required of thoughtfulness are all in jeopardy. And this phenomenon is hardly noticed. After all, it is not that thinking has been vanquished. Rather, the response now encouraged is of a meagre kind, merely satisfying the requirements of internal and external performance management. Emerging is a thoughtlessness of a particular kind, a malign thoughtlessness. The intense, inward and untrammelled thoughtfulness that is fading is an opportunity cost, but invisible at that, of contemporary transformations of the university. 
It is at this point that the key matter before us has to be addressed and we may also pull together a number of strands in our explorations. What might be meant by a thoughtful university? A university that not just happens to think but rather a university that is organized to think. A university the thought processes of which are maximised. It becomes a university full of thought, even about itself and its possibilities; a thoughtful university.

In the twenty-first century, universities are complex organisations serving many ends. In turn, their knowing efforts are increasingly being managed so as to maximise exogenous ends, of income, of impact, of position and of competitive distinctiveness. But does it think about such matters? Does it $d w e l l$ on such matters?

What is at issue are not exogenous ends in themselves. The matter is the effect that exogenous ends have upon knowing and thinking efforts. Are those efforts expanded or diminished? Are they being steered by pernicious ends or by ends that are intrinsically linked to wellbeing? "Knowledge production", "knowledge transfer" and now "knowledge exchange": the metaphors portray a sense of knowledge entities as having a three-dimensional character. This knowledge can be produced and transferred and even exchanged for some kind of return; knowledge is objectified and reified. It becomes a thing, susceptible to being bartered for a return of some kind. In this knowledge management, there is no sense of knowledge for wellbeing.

Criteria of thought are therefore called for. Especially, what are called for are criteria that might demarcate worthwhile thoughtfulness from malign thoughtlessness (as termed earlier). Or, better still, what are called for here are criteria that would provide necessary and sufficient conditions of the thoughtful university - so that we would know it when we saw it.

Key here is the university as an organization. However, we currently lack a framing of the required kind and it is not immediately evident where suitable resources might be found. Helpful here would be Luhmann's systems theory, which (2003) considers the organization as a system, and the proclivity of an organisation to be a self-maintaining system. This opens the consideration that the thoughtful university is an organizational system with its own systematic thought processes that enable the university to go on learning about itself and so also go on developing itself amid changing circumstances.

Also helpful as a resource, as intimated, could be the structure-agency debate. Work has been undertaken to deploy that debate in the context of the university but, so far, emphasis has understandably been placed at the level of academic life (Canaan and Shumar, 2008). Rather missing so far is much of an 
attempt to examine the extent to which the university has agency of its own. What is it for a university to think, if it is hedged in by deep structures that propel it this way and that? The question opens to two lines of inquiry.

On the one hand, Roy Bhaskar's philosophy of critical realism points to layers of presence underlying the empirical features of entities in the world. Bhaskar (2008) insisted on an ontological dimension in understanding the world. In his philosophy, beneath the empirical level (which is immediately available for inspection) lies the actual level (in which phenomena are present but which may not be visible) and the real level (at which level lie structuring mechanisms with causal properties).

That idea is potent here, in the context of the university, in which global forces are acting upon universities as "generative mechanisms" (Bhaskar, 2007: $36-7$ ), but the idea can be radicalised. For we can observe that the university not only possesses an ontology but that - paradoxical as it may seem - its social ontology is widening, as the national and global forces of finance, economy, politics, audit and culture come to exert ever wider and more profound influences on universities. The thought characteristic of the university as a thinking organisation is not so much undermined or hollowed out but rather is subtly steered by dynamic and deep global structures. However, this widening of the university's social ontology opens possibilities for the university, even though this widening constrains the university.

The second line of inquiry here is to turn to the other pole in the structureagency polarity. A thoughtful university has to have agency of its own. Real thought is untrammelled thought and requires space, powers of thought and a will to exercise thought, even in difficult circumstances. This is the ground that List and Pettit explored in their (2011) ground-breaking book on Group Agency. Just what is it for an organization to possess agency different from the agency of that of its members? In the limit, after all, in exercising such agency, an organization may act and express its agency even without the support of its members; although this would be an occurrence in the limit since its agency calls also for a measure of support from and the coordination of the views of its members.

The thoughtful university, accordingly, would be one that both possessed powers of collective thought and that sought to mobilise that thought. And this thought would have to include thought about the university itself. But such thought, if it is serious thought, cannot be casual thought about the university. It cannot simply amount to quasi-ideological expressions of the interests of the academics and the managers as they vie against each other or of the separate disciplines as they attempt to advance - or even to restore - their own positions in the academic hierarchy. For such thought to have substance, 
it would need to be grounded in an appreciation of the deep social ontology of the university - as it moves within its national and global structures - and elevated by a collective concern for the world and collaborative thinking as to the university's possibilities in this world.

\section{Glimpsing Thoughtfulness}

Where, then, if at all, might thoughtfulness have purchase here? Prima facie, thoughtfulness now becomes the university allowing itself to be a site in which such battles of ideas can be fought. Provided that those conflicts about the university that we observed - between "private" and "public", between the sciences and the humanities, between "truth" and "performance" (or "impact"), between the economy and culture and so on - can be played out on campus, then we can talk seriously about the thoughtful university. Each position would be subject to interrogation by other parties. The thinking university would be sponsoring critical dialogue about its own possibilities. The thoughtful university would apply its thinking to itself and seek the possibilities that flow from that self-awareness. It would become thoughtfully reflexive.

But this position would amount only to a slight advancement on MacIntyre's idea of a university - which we encountered earlier. MacIntyre (2011:74), it will be recalled, has lamented that "the contemporary research university is ... by and large a place in which certain questions go unasked". Here lies - if we are not careful - the trap of seeing the university simply as a debating society writ large. Such a conception is to be found, in different ways, in Derrida (in his idea of "the university without condition"), in Habermas (in his idea of an unconstrained speech situation) and Readings (in his idea of "dissensus") but the debating conception of the university cannot do justice to the scope of the challenges as marked out here.

The university, we have seen, has to be understood both as a space of ideas and for reasoning and also for identifying and thinking through the structures that bear upon it as an institution. While recognizing the university as an institution, MacIntyre focused his early (1985) attention on the virtues or qualities that were, for him, inherent in academic life; but the university qua institution has to be done full justice if the potential of the university as a site of cognition is to be realised.

At its best, accordingly, in this situation, thoughtfulness at the level of the university might be considered to contain the following five elements: (i) an examination of the empirical features of the university; (ii) a disinterring of the components of the university's social ontology, in attempting to discern the 
large global, regional and national forces acting on it; (iii) a critique of those components; (iv) a keeping alive of the concepts of the constellation of reason; and (v) a will, in that collective thoughtfulness, to discern and even to imagine possibilities for the university that just might enhance wellbeing in the world.

In their corporate planning, there is often talk within universities of "horizon scanning", and that idea resonates here; but it is evident - not least from this identification of necessary conditions of university thoughtfulness - that that idea needs to expanded. This university thoughtfulness - thoughtfulness about and within a particular university itself and about its possibilities in the world - would be expansive, multi-disciplinary, imaginative and methodologically eclectic, and it would encompass qualitative, quantitative, historical, comparative, conceptual, theoretical and normative inquiries that focused on the particular university in question.

Certainly, across the social sciences (including anthropology) and philosophy, we find just this range of scholarly and research concerns in contemporary academe, marked by an attempt to offer critiques of the university. However, this thoughtfulness has a dismal tone attaching to it. The sociologists lament the interests bound up in the marketization of the university, at once private interests and the interests of corporate organizations that find their expression in "academic capitalism" (Slaughter and Rhoades, 2004), and the philosophers and social theorists worry that the university is no longer a space of reason as such (cf Bakhurst, 2011). These plaintive readings have virtue, in calling the entrepreneurial university and the corporate university - not to mention the bureaucratic university - to account. But the question is whether or not such critiques, largely of unremitting gloom, constitute the only readings of the university. Might there grounds for a more optimistic reading of the university's unfolding cognitive culture?

Widening Social Ontology - and Widening Universals

Two phenomena can be discerned which are fundamental to the narrative here but neither has - to my knowledge - been given much attention. The first is that the social ontology of the university is not merely on the move but that, with its dynamic and complexity, this social ontology of the university is widening. We do not need to peer back to mediaeval times to the origins of the modern university: even one hundred years ago, we can say that the social ontology of the university was a thin affair. Largely, what you saw was what there was to see. With the university being but a small institution on the fringe of society, it 
had little by way of a societal underpinning. That has changed fundamentally. Now, we can only dimly grasp at an understanding of the university's wide and ever-widening social ontology.

Terms such as "global economy", "neoliberalism", "state steering", "cognitive capitalism", "the evaluative state", and "the digital revolution" are but weak efforts to attempt to uncover the steering structures at work in the deep layerings of the university. Bhaskar's (ontological) philosophy of Critical Realism has direct application here for beneath the immediate empirical features of the university is an "actual" layer of national and transnational frameworks and beneath that is a subterranean level of the "real", those global forces acting more or less independently of human intention and which yet supply "generative mechanisms" (2007) that act to exert steering impulse upon universities worldwide.

All that has developed in the last one hundred years or so. And we can see that this largely hidden complexity is continuing to grow. The world will continue to become evermore inter-connected in time and space and the digital revolution will spawn new modes of communication (with the world and amongst peoples). Also, large collective concerns - over demography, security, ageing, resources, population movements, energy, democracy, openness, surveillance cyber-wars and so forth - will assuredly come to exert an ever growing influence, and not least on universities.

Secondly, the story of the university cannot be adequately adumbrated without recourse to large concepts; we may even call them universals. One reading of postmodernism was the suggestion that the universals of reason with which the university had come to be associated - knowledge, truth, reason itself, critical thought - were in the dock, suspected of being empty "grand narratives" towards which only "incredulity" was due (Lyotard, 1984:37). All that mattered in the postmodern society was a measuring of the outputs of a system; a position that arguably we have reached precisely in relation to the contemporary position of universities.

But the universals gambit should not be abandoned just yet, if ever. This very point is at the heart of a remarkable book entitled Contingency, Hegemony, Universality by Judith Butler, Ernesto Laclau and Slavoj Zizek (2000). For Butler, indeed, there is nothing untoward about this point as to universals marking a site of conflict: "Maintaining that universality is a "site of contest" has become something of an academic truism". She then adds "but considering the meaning and promise of that contest has not". (39) The book, accordingly, develops a conversation between the three authors as to the character and the significance of contest in and around universals. 
This perspective and the recuperation of the very idea of universals is crucial for our inquiry here. Within the university, new universals are being given even more attention. The emergence of a global discourse with terms such as "markets", "competition", "success", "world-leading", "skills" and "entrepreneurialism" marks not the end of universals but the emergence of new universals for the university and, in the process, a displacement of the constellation of reason by the constellation of utility.

The question arises as to whether this is "the end times" (Zizek, 2011) for the university or whether this situation is but a stepping-stone to a new set of understandings of the university. In fact, surely, we see the signs of just this latter possibility, even now. Terms such as "civic", "public", "engagement", "community", "wisdom", "wellbeing", "social justice" and "ecology" are now being put forward, in various combinations and forms, to glimpse possibilities for the university ("public benefit", "community engagement", "ecological university" and so forth). Are we not seeing here a new constellation of universals struggling to emerge? We might term it the constellation of otherness. If characteristically, the university associated with the constellation of reason was a university-in-itself, and the university associated with the constellation of utility has been a university-for-itself, the university associated with the constellation of otherness will be a university-for-the-other.

10

Feasible Utopias

The point is that, in all of this, new spaces are already opening not just for thinking about the university but for thinking about the university anew. And many universities around the world, both individually and collectively, are doing just that, exploring just what "engagement", "civic", "community", "public", "wisdom" and "openness" might mean in an interconnected global world. In so doing, they are moving well beyond the boundaries of the "entrepreneurial university".

It is not only that universities are, as it were, reaching out practically to society and indeed to the world in new ways. For example, across the world, universities are investigating ways in which they might respond to the United Nations' Development Goals, or are looking to develop serious programmes of civic engagement. Rather, it is that they are - in the process - stretching the conceptual hinterland of the university. Now, the universals being legitimately 
associated with university, far from thinning, are widening and thickening. Our understanding of what a university is all the time growing.

The limits here are, in part, those of the university's imagination. The phrase "in part" is crucial. For the university has to live in the world, the real world, the world of the real (to draw again on Bhaskar's (2008) use of the term). It will still continue to be framed substantially by its underlying steering mechanisms but, as remarked, they are themselves becoming more complex, and are opening the ways for otherness to be glimpsed. Glimpses of the university's possibilities, therefore, have to heed the domain of the real. Utopias of the university can be glimpsed but, if they are to be taken seriously, they have to be feasible; feasible utopias indeed (Barnett, 2018). And so ideas of the future university need to be come before a tribunal to be tested.

Such a tribunal would consist of certain criteria of adequacy. Criteria that such imaginative ideas need to satisfy might include those of (i) feasibility itself, (ii) scope (the potential to open itself to different angles, spaces and perspectives), (iii) emergence (the powers of an entity to go on developing amid the exigencies that present themselves), (iv) temporal flexibility (the capacity of an idea to play itself out in different timeframes), (v) locale (having meaning locally, nationally and globally), and (vi) wellbeing (having an intent to improve the world in some way). (See Barnett (2013: chio) for a fuller exposition of these criteria.) The point is that it is not just that imaginative ideas are needed if the university is to take advantage of the spaces that are opening - and thereby to realise its agentic possibilities - to it but that any such imaginative ideas have to satisfy certain conditions. Imagination is a necessary but insufficient condition of what it is to realize the university.

Thought in the university has been going through a thin time, but this downtime may be only a temporary matter. "The entrepreneurial university" and "the corporate university" have been holding the high ground, with the thoughtlessness that accompanies these university forms - in uncritical acceptance of ideologies of marketing, over-disciplined thought (channelled by economic and managerial reason), diminution of large horizons, competition between disciplines, an over-weaning bureaucratic managerialism, knowing and learning efforts steered by market considerations, and a disinclination for the university to be self-reflexive. It is these last on which we have focused in this paper: a narrowing of the cognitive culture of the academy and the willingness 
- or lack of willingness - of the university to ask questions of itself in that context, as to what it is to be a university in the twenty-first century, and to think seriously about its possibilities and to critique them.

My thesis has been that dismal readings of the contemporary university - as a diminishing space of thought about itself - are understandable. The underlying generative mechanisms that have evolved over the past hundred years or so have acted largely not exactly to close reflexive thought entirely but to thin it and channel it. Certainly, there have been locations and episodes that counter this broad generalisation - both in countries, and at certain points of national and cross-national policy-making (for example, in the higher education policy framework of South Africa, oriented to a philosophy of "hope", and in the part played by universities, especially their students, in the national reconstruction in Chile following the last dictatorship) - but the general tide has been in this narrowing direction, as the world has seen the rise of the entrepreneurial university. However, this situation should not be felt to constitute the end game (cf Zizek, 2011). To take up that stance will only serve the interests of the instrumentalists. Indeed, many universities around the world are now thinking through their responsibilities to and possibilities in the world, in civic, social and ecological directions. They are becoming thoughtful about themselves.

The university of reason has been overtaken by the university of utility: thesis and antithesis. But, then, there may be yet more to come. We are not at the end times for the university. Much like the Mobius strip (Zizek, 2009), the thoughtless university and the thoughtful university not just attach to each other but even run into each other, taking turns in their prominence.

This juxtaposition, it is evident, entails no definite synthesis. To the contrary, spaces are opening for new thought, for new directions of travel, and in different directions. Rather than any particular kind of synthesis, these spaces are likely to offer multiple "lines of flight" (Deleuze and Guattari, 2007; Guattari, 2016) in which the university may search for ways of finding new connections with the wider society, at local, national and global levels. This would be a new layering, a splicing of interweaved possibilities on top of the university of reason and the university of utility. Key here is that this new kind of university, a university for-the-other, will call for new and serious thought about the university itself. This will be the university finding a new kind of reflexivity, in thinking about itself.

This is a utopia and it is a feasible utopia. It is feasible in that we can already glimpse embryonic manifestations of it. More especially, it is feasible in that it has to find some kind of fit with its social ontology: it has to live with that "real" dimension of its being. It has to live, and is already living, in the real world. 


\section{References}

Bakhurst, D. (2011) The Formation of Reason. Oxford and Malden, MA, Wiley-Blackwell. Barnett, R. (2013) Imagining the University. Abingdon and New York, Routledge.

Barnett, R. (2018) The Ecological University: A Feasible Utopia. Abingdon and New York, Routledge.

Beck, U. (1992) Risk Society: Towards a New Modernity. London, Sage.

Bhaskar, R. (2007/1998) 'Philosophy and Scientific Realism' in M. Archer, R. Bhaskar, A. Collier, T. Lawson and A. Norrie (eds) Critical Realism: Essential Readings. London and New York, Routledge.

Bhaskar, R. (2008) A Realist Theory of Science. London and New York, Verso.

Bloom, A. (1987) The Closing of the American Mind. London, Penguin.

Boutang, Y.M. (2011) Cognitive Capitalism. Cambridge, Polity.

Butler, J., Laclau, E. and Zizek, S. (200o) Contingency, Hegemony and Universality. London and New York, Verso.

Canaan, J.E. and Shumar, W. (2008) Structure and Agency in the Neoliberal University. New York and Abingdon, Routledge.

Critchley, S. (2001) Continental Philosophy: A Very Short Introduction. Oxford, Oxford University Press.

Davies, M. and Barnett, R. (eds.) (2015) The Palgrave Handbook of Critical Thinking in Higher Education. New York and Basingstoke, Palgrave Macmillan.

Deleuze, G. and Guattari, F. (2007/1987) A Thousand Plateaus: Capitalism and Schizophrenia. London and New York, Continuum.

Feyerabend, P. (2001) Conquest of Abundance: A Tale of Abstraction versus the Richness of Being. Chicago and London, University of Chicago.

Giroux, H. (2015) Truthout: 'Interview with Henry Giroux': http://www.truth-out.org/ news/item/14331-a-critical-interview-with-henry-giroux.

Guattari, F. (2016) Lines of Flight: For Another World of Possibilities. London and New York, Bloomsbury.

Hassan, R. (2003) The Chronoscopic Society: Globalization, Time and Knowledge in the Network Economy. New York, Peter Lang.

Heidegger, M. (2001/1971) Poetry, Language, Thought. New York, Harper and Row.

Heidegger, M. (2004/1954) What is Called Thinking? New York, Harper and Row.

Heidegger, M. (2007/1978) Basic Writings. Abingdon and New York, Routledge.

Kant, I. (1992/1798) The Conflict of the Faculties. Lincoln and London, University of Nebraska.

Knorr Cetina, K. (1999) Epistemic Cultures: How the Sciences Make Knowledge. Cambridge, MA, Harvard University.

Knorr Cetina, K. (2013) 'Culture in global knowledge societies: knowledge cultures and epistemic cultures', Interdisciplinary Science Reviews, 32 (4) 361-375. 
Leavis, F.R. (1969) English Literature in our Time and in the University. London, Chatto and Windus.

List, C. and Pettit, P. (2011) Group Agency: the possibility, design, and status of corporate agents. Oxford, Oxford University Press.

Luhmann, N. (2003) 'Organization', ch3 in T. Bakken and T. Hernes (Eds.) Autopoietic Organization Theory: Drawing on Niklas Luhmann's Society Systems Perspective. Denmark, Copenhagen Business School.

Lukasewicz, J. (1994) The Ignorance Explosion. Ottawa, Carleton University.

Lyotard, J.-F. (1984) The Postmodern Condition: A Report on Knowledge. Manchester, University of Manchester.

MacIntyre, A. (1985) After Virtue: a study in moral theory. London, Duckworth.

MacIntyre, A. (2011) God, Philosophy, Universities: A Selective History of the Catholic Philosophical Tradition. Lanham, Maryland, Rowman and Littlefield.

McLaren, P. and Jaramillo, N.E. (2012) 'Not Neo-Marxist, Not Post-Marxist, Not Marxian, Not Autonomist Marxism: Reflections on Revolutionary (Marxist) Critical Pedagogy', Cultural Studies: Critical Methodologies, $\mathrm{xx}(\mathrm{x}) \mathbf{1}-12$.

Molesworth, M., Scullion, R. and Nixon, E. (Eds.) (2011) The Marketisation of Higher Education and the Student as Consumer. Abingdon and New York, Routledge.

Murphy, P. (2009) 'Creativity and Knowledge Economies', in M.A. Peters, S. Marginson, and P. Murphy, op. cit.

Newman, J.H. (1976) The Idea of a University. ed I.T. Ker. Oxford: Clarendon Press.

Peters, M.A. (2009) 'Education and the Knowledge Economy', in Peters, Marginson and Murphy, op. cit.

Peters, M.A. (2013) Education, Science and Knowledge Capitalism: Creativity and the Promise of Openness. New York, Peter Lang.

Peters, M.A., Marginson, S. and Murphy, P. (2009) Creativity and the Global Knowledge Economy. New York, Peter Lang.

Peters, R.S. (1970) Ethics and Education. London, George Allen and Unwin.

Readings, B. (1997) The University in Ruins. Cambridge, MA, Harvard University.

Slaughter, S. and Rhoades, G. (2004) Academic Capitalism and the New Economy: Markets, State and Higher Education. Baltimore, Johns Hopkins University.

Stiegler, B. (2014) For a New Critique of Political Economy. Cambridge, Polity.

Stiegler, B. (2015) States of Shock: Stupidity and Knowledge in the Twenty-First Century. Cambridge, Polity.

Virilio, P. (2005/1984) Negative Horizon: An Essay in Dromoscopy. London and New York, Sage.

Wilsdon, J. et al. (2015) The Metric Tide: Report of the Independent Review of the Role of Metrics in Research Assessment and Management. DOI:10.13140/RG.2.1.4929.1363. Zizek, S. (2009) The Parallax View. Cambridge, MA: MIT.

Zizek, S. (2011) Living in the End Times. London and New York, Verso. 